\title{
STATISTICAL DATA ANALYSIS WHICH RESULT FROM THE BIO-DIAGNOSIS AND BIO-TREATMENT OF INJURED RATS WITH THE HYPERLIPIDEMIA AND HYPERGLYCEMIA DISEASES
}

\author{
HANAN F ALY ${ }^{1 *}$, HOWAIDA I ABD-ALLA ${ }^{2}$, SANAA A ALI ${ }^{1}$, MOHAMED M MAMDOOH ${ }^{3}$, REDA ABO ALEZ ${ }^{3}$, \\ MOHAMMED T ABU-KRISHA ${ }^{3}$
}

${ }^{1}$ Department of Therapeutic Chemistry, National Research Centre, Dokki 12622, Giza, Egypt. ${ }^{2}$ Department of Chemistry of Natural Compounds, National Research Centre, Dokki 12622, Giza, Egypt. ${ }^{3}$ Department of Systems and Computer Engineering, Faculty of Engineering, Al-Azhar University, Cairo, Egypt. Email: hanan_abduallah@yahoo.com

Received: 02 August 2016, Revised and Accepted: 30 August 2016

\section{ABSTRACT}

Objective: This study in bioinformatics aims to investigate the potential effect of Ipomoea tricolor and Sophora tomentosa on liver function enzymes activity, serum lipid profile, oxidative stress biomarkers, and on blood glucose in high fat diet-induced hypercholesterolemia (HC) and STZ-induced hyperglycemia (HG) in rats.

Methods: Blood glucose level, liver function enzymes, alanine aminotransferases and aspartate aminotransferases, alkaline phosphatase, and lactate dehydrogenase (LDH) were determined. Besides, lipid profile including total cholesterol (TC), triacylglycerol (TG), total lipid, and high-density lipoprotein-cholesterol was investigated. Moreover, oxidative stress biomarkers, lipid peroxide, and nitric oxide as well as non-enzymatic antioxidant, glutathione (GSH) were also examined in different therapeutic groups.

Results: A significant increase in blood glucose level, liver function enzyme activities, LDH, lipid profile and oxidative stress markers, while significant decrease in LDH-C and GSH level in HC-HG induced rats compared to control one. A marked amelioration in all biochemical parameters under investigation on treatment of HC-HG rats with $I$. tricolor and S. tomentosa with different fluctuating percentages of improvement. Histopathological examination of liver and pancreas was also performed and declared HC-HG showed congestion in portal vessels and sinusoids with mild centrilobular hepatocyte degeneration, marked hepatocyte ballooning and hydropic degeneration, while HC-HG treated rats with I. tricolor and S. tomentosa showed normal lobular hepatic architecture with mild sinusoidal dilatation and congestion. On the other hand, a histological organization of pancreas of HC-HG rats showing disarrangement changes in pancreatic blood vessels and interlobular duct as well as disordered in acini. The treatment of HC-HG rats with I. tricolor and S. tomentosa showed enhancement in Langerhans cells and restore of most pancreatic tissue in comparison with standard drugs.

Conclusion: The statistical results showed that each extract ameliorated high blood glucose level liver injury, HC and oxidative stress indicating relieving of oxidative damage associated with the complexity of HG and HC. These results demonstrated that these two plants extracts may be a candidate intelligent antioxidant, hypolipidemic, hypoglycemic, and hepatoprotective nutraceuticals which need further clinical investigation to be applied effectively to reduce perturbation in HC associated diabetes.

Keywords: Ipomoea tricolor, Sophora tomentosa, Lipid profile and liver function enzymes, Endothelial dysfunction markers, Statistics and image recognition, Histopathological analysis.

(C) 2016 The Authors. Published by Innovare Academic Sciences Pvt Ltd. This is an open access article under the CC BY license (http://creativecommons. org/licenses/by/4. 0/) DOI: http://dx.doi.org/10.22159/ajpcr.2016.v9s3.14439

\section{INTRODUCTION}

Some of recent researches in bioinformatics are done for using natural extracts in treating of compound and complex diseases as hyperlipidemia and hyperglycemia (HG) diseases [1].

Hyperlipidemia is known to be the leading risk factor for atherosclerosis. Abnormal increases in serum total cholesterol (TC), triacylglycerol (TG), and high-density lipoprotein-cholesterol (HDL-C) levels are among the indicators of atherosclerosis development, while elevated serum HDL-C is known to be protective against the development of atherosclerosis [2]. Oxidative stress plays a major role in the process of endothelial damage and atherosclerosis. Reactive oxygen species (ROS) can oxygenate and modify low-density lipoprotein-cholesterol (LDL-C) to form oxidized LDL-C, leading to the accumulation of cholesterol in phagocytes and to the formation of foam cells, promoting the development of atherosclerosis [2]. Thus, reduction in plasma cholesterol level could improve the endothelial cell function and reduce vascular inflammation [3]. The most commonly used lipid regulators at present are statins and fibrates. Although the statins overall safety profile is very good, some concerns have been raised regarding the nature of the side effects, i.e., rhabdomyolysis, essentially because they seem completely linked to the mechanism of action of this class of drugs. In addition, statins do not work for all patients [4]. Therefore, there is a need for drugs that would not target an enzymatic pathway, as statins do, or will not induce global changes of gene expression, as fibrates do, but instead directly target cholesterol present in the blood flow.

Plant phenolic compounds are important constituents known as natural tender drugs. Compounds other than the bioactive flavonoids as alkaloids, coumarochromones, saponins, triterpene glycosides, phospholipids, polysaccharides, oligostilbenes, and fatty acids are reported in many Sophora species [5]. The roots of Sophora flavescens is one of the bitter and cold Chinese medicines commonly used to remove lung heat have been used to counteract diabetes mellitus (DM) and exerted good clinical effects for diabetic patients in some folk hospitals in Fujian province [6]. Thus, this study aims to evaluate the possible beneficial effect of Ipomoea tricolor and Sophora tomentosa crude extracts on serum lipid parameters in hypercholesterolemic (HC) and hyperglycemic $(\mathrm{HG})$ rats as well as the histological examination of the liver and pancreas were carried out to confirm the biochemical findings and also to develop and utilize effective natural lipid and blood glucose regulators for more aggressive treatment of $\mathrm{HC}$ associated with HG. 


\section{METHODS}

\section{Plant materials}

Aerial parts of the I. tricolor Cav. (Convolvulaceae) and the S. tomentosa L. (Fabaceae) were collected in May 2014 from El-Qanater, Qalyubia Governorate. The identification of the plants material was performed by TreasLabib, consultant of plant taxonomy at the Ministry of Agriculture and ex-director of Orman Garden, Giza, Egypt. A voucher sample is kept in the herbarium of National Research Centre (NRC), Egypt.

\section{Preparation of $I$. tricolor and $S$. tomentosa extracts}

Each dried powdered aerial parts $(500 \mathrm{mg})$ of $I$. tricolor and $S$. tomentosa was, separately extracted by cold percolation in ethanol for $24 \mathrm{hrs}$. Each extract was, separately, recovered and ethanol was further added to the plant material, and the extraction was continued. The process was repeated three times and pooled together. The extracts were, separately, concentrated under reduced pressure $(22-26 \mathrm{mmHg})$ at $40^{\circ} \mathrm{C}$ to yield brown to greenish brown oily crude residue; 14.1 and $23.1 \mathrm{~g}$ of I. tricolor and S. tomentosa, respectively. They were maintained in dark glass container, at $\left(-4^{\circ} \mathrm{C}\right)$ until use.

\section{Chemicals}

All chemicals and reagents were purchased from Biodiagnostic Company for diagnostic and research reagents, Egypt. Reference drug (atorvastatin) was purchased from NOVARTIS Pharmaceuticals. ELISA kits were provided by Invitrogen (U.S.A.) for IL-10, Eiaab (U.S.A.) for both VCAM-1 and ICAM.

\section{Induction of $\mathrm{HC}$}

HC was induced in rats according to the method of reference [7], by feeding rats high-fat diet(cholesterol), cholesterol was orally administrated at a dose of $30 \mathrm{mg} / 0.3 \mathrm{~mL}$ olive oil $/ 1 \mathrm{~kg}$ animal 5 times a week for 12 consecutive weeks, lard fat was mixed with normal diet ( $1 \mathrm{~kg}$ of animal lard was added to $5 \mathrm{~kg}$ of normal diet), the occurrence of HC was determined by measuring the lipid profile (TC, LDL-C, HDL-C, $\mathrm{TG}$ ), the $\mathrm{HC}$ rats were only used.

\section{Induction of diabetes}

Type 2 diabetes was induced by intraperitoneally injection of a single dose of streptozotocin (STZ) $(45 \mathrm{mg} / \mathrm{kg}$ body weight dissolved in 0.01 M citrate buffer immediately before use [8]. After injection, animals had free access for food, water and were given $5 \%$ glucose solution to drink overnight to encounter hypoglycemic shock. Animals were checked daily for the presence of glycosuria [9]. Animals were considered to be diabetic if glycosuria was present for 3 consecutive days. After 3 days of STZ injection fasting blood samples were obtained and blood sugar level was determined $(\geq 300 \mathrm{mg} / \mathrm{dL})$.

\section{Routs of administration}

$\mathrm{HC}$ rats received an oral dose of $2 \mathrm{mg} / \mathrm{kg}$ body weight dissolved in distilled water of the anti-HC reference drug; atorvastatin, dissolved in distilled water orally by gastric intubation for 4 weeks.

\section{Experimental design}

\section{Rats}

A total of 70 Male Wister rats weighing $150 \pm 10 \mathrm{~g}$ were provided from the animal house of the NRC and housed in a temperature controlled environment $\left(26-29^{\circ} \mathrm{C}\right)$, in steel mesh cages on wood-chip bedding, with a fixed light/dark cycle for 2 weeks as an acclimatization period with free access to water and food ad-libitum. This study is approved by the Ethical Committee of the NRC, Egypt, which provided that the animals will not suffer at any stage of the experiment. Animals were randomly divided into seven equally sized groups of 10 rats each $(\mathrm{n}=10)$ as follows:

Group 1: Normal healthy control rats, Groups 2 and 3: Normal rats treated orally with $250 \mathrm{mg} / \mathrm{kg}$ body of crude extract of $I$. tricolor and S. tomentosa, respectively, for 30 days. Group 4: Is considered as diabetic group which classified as follows: Groups 5 and 6: Diabetic rats oral administered $250 \mathrm{mg} / \mathrm{kg}$ body weight crude methanolic extracts of I. tricolor and S. mentosa for 30 days, respectively. Group 7: Diabetic rats administered orally antidiabetic glibenclamide reference drug $10 \mathrm{mg} / \mathrm{kg}$ body weight daily for 30 days [10] and oral dose of $2 \mathrm{mg} / \mathrm{kg}$ body weight of the anti-HC reference drug; atorvastatin [2].

Blood collection and tissue sampling

By the end of the experiment ( 4 weeks), the animals of different groups were fasted for $12 \mathrm{hrs}$, weighted then blood samples were collected from the sublingual vein, then left to coagulate at room temperature and centrifuged at $3000 \mathrm{rpm}$ for 15 minutes. The clear, non-hemolyzed, and supernatant sera were quickly removed and kept at $-80^{\circ} \mathrm{C}$ till used for biochemical investigations of lipid profile and liver function.

Then, animals sacrificed using diethyl ether anesthesia and liver tissue was rapidly excised and accurately weighed; $0.5 \mathrm{~g}$ from each liver was homogenized in $5 \mathrm{~mL}$ phosphate buffer using $(\mathrm{pH}$ 7.4) electrical homogenizer. The clear homogenate was used for estimation of nonenzymatic antioxidant defense system; lipid peroxide and nitric oxide (NO).

\section{Biochemical examination \\ Lipid profile and liver function enzymes}

Serum total lipids concentration was determined according to the method of reference [11], serum triglycerides (TG) concentration was determined according to the method of Fassati and Prencipe [12], serum total cholesterol (TC) level was estimated according to the method of Allain [13], and serum HDL-C concentration was measured according to the method of Lopez-Virella [14]. Serum LDL-C concentration was determined according to the equation of Friedewald [15]. Glucose was determined in blood serum using colorimetric kits [16]. Alanine aminotransferases (ALT) and aspartate aminotransferases (AST) and alkaline phosphatase (ALP) enzyme activities were assayed by Reitman and Frankel [17] and Belfield and Goldberg [18], respectively. Lactate dehydrogenase (LDH) enzyme activity was measured according to El-Baz et al. [19].

\section{Endothelial dysfunction markers}

Liver NO was determined according to the method of Montgomery and Dymock [20]. Glutathione (GSH) level was assayed in liver homogenate according to the method of Beutler et al. [21]. Liver malondialdehyde (MDA) level as a lipid peroxidation marker was estimated according to the method of Satoh [22].

\section{Histopathological analysis}

Parts of liver and pancreas were kept in neutral buffered neutral formalin for 8 hours for fixation then processed in automatic processors and paraffin blocks were obtained. Sections of 3-5 $\mu$ thickness were stained using Hematoxylin and Eosin ( $\mathrm{H}$ and $\mathrm{E}$ ) stain to assess the cellular changes induced in the aorta in all treatment modalities; like the presence of foam cells in subintima as well as media, interruption of elastic lamina and presence or absence of fibrosis. The slides were examined and photographed under a light microscope at a magnification power of $\times 200$

\section{Statistical analysis}

Data presented as mean \pm standard deviation (SD), $n=10$. Statistical analysis was performed using one-way analysis of variance SPSS (version 7) computer program and Co-state computer program, where unshared letter is significant at $\mathrm{p} \leq 0.05$.

\section{RESULTS AND DISCUSSION}

\section{The hypoglycemic effects of $I$. tricolor and $S$. tomentosa}

These results (Table 1) indicated insignificant change in glucose level in healthy negative control rats treated with I. tricolor and S. tomentosa extracts as compared to normal control rats. Blood glucose level of diabetic rats showed a significant increase $(287.50 \%)$, as compared to normal control rats. The treatment of diabetic rats with I. tricolor and 
S. tomentosa extracts declared significant increase in blood glucose level with the percentage of improvement $153.31 \%$, while the percentage of amelioration reached to $169.76 \%$ with $S$. tomentosa as compared to standard drugs (179.57\%) (Table 1$)$. Table 2 revealed insignificant change in liver enzyme activities AST, ALT, and ALP as well as LDH were detected in healthy rats' orally administrated $I$. tricolor crude extracts of $S$. tomentosa comparing to normal control rats. However, HC-HG rats exhibited significant increase in enzyme activities; AST, ALT, ALP and LDH (129.77\%, 155.73\%, 117.99\% and 56.74\%, respectively) as compared to normal control one.

The treatment of HC-HG rats with I. tricolor and S. tomentosa extracts as well as standard drugs showed insignificant change in AST and LDH enzyme activities as compared to normal control rats. However, ALT and ALP enzyme activities recorded insignificant change with the treatment of $S$. tomentosa extract, while, on treated HC-HG rats with I. tricolor and reference drugs showed significant increase in ALT and ALP enzyme activities with improvement percentages reached to $97.83 \%$ and $85.24 \%$, respectively, for ALT and 85.56 and $88.45 \%$, respectively, for ALP (Table 2).

These results show that blood glucose level is significantly increased in diabetic rats with percentage reached to $205.04 \%$, as compared to normal rats. This may be explained on the basis of, the loss of insulin effect on liver leads to glycogenolysis and increase in hepatic glucose production. In addition, the abnormalities of triglyceride storage and lipolysis in insulin-sensitive tissue such as liver are considered as an early manifestation of conditions characterized by insulin resistance [23]. Moreover, diabetes induction with STZ leads to inflate and ultimately degenerate the Langerhans islets $\beta$-cells [24], and consequently, hydrogen peroxide and hydroxyl radicals are generated. The generation of free radicals such as hydrogen peroxide, superoxide anion radicals, and hydroxyl plays a key role in the cytotoxicity of STZ [25].

Significant reduction in serum glucose level was observed in all treated groups as compared to HC-HG rats, mainly by I. tricolor extract (51.72) followed by $S$. tomentosa (35.27). This glucose-lowering effect of extracts may be attributed to gluconeogenesis and the regulation of serum lipid levels. Therefore, these results-indicates the link between anti-HG and hypolipidemic activities of both extracts.

Plants may act on blood glucose through different mechanisms including facilitating insulin's activity, acting as potential insulinlike substances, inhibiting insulinase activity, and increasing the

Table 1: Comparative effects of $I$. tricolor and $S$. tomentosa supplementation on blood glucose level in control and different therapeutic groups

\begin{tabular}{|c|c|c|}
\hline Groups & Parameters & Glucose $(\mathrm{mg} / \mathrm{dL})$ \\
\hline Negative control & Mean \pm SD & $94.25 \pm 6.13^{d}$ \\
\hline \multirow[t]{2}{*}{ Negative treated with I. tricolor } & Mean \pm SD & $94.73 \pm 5.53^{\mathrm{d}}$ \\
\hline & $\%$ Change to control & 0.51 \\
\hline \multirow[t]{2}{*}{ Negative treated with S. tomentosa } & Mean \pm SD & $96 \pm 8.28^{\mathrm{d}}$ \\
\hline & $\%$ Change to control & 1.85 \\
\hline \multirow[t]{2}{*}{ HC-HG } & Mean \pm SD & $287.5 \pm 25.00^{\mathrm{a}}$ \\
\hline & $\%$ Change to control & 205.04 \\
\hline \multirow{2}{*}{ HC-HG treated with I. tricolor } & $\%$ Change to control & 51.72 \\
\hline & $\%$ of improvement & 153.31 \\
\hline \multirow[t]{3}{*}{ HC-HG treated with S. tomentosa } & Mean \pm SD & $127.50 \pm 6.40^{\mathrm{bc}}$ \\
\hline & Change to control & 35.27 \\
\hline & $\%$ of improvement & 169.76 \\
\hline \multirow[t]{3}{*}{ HC-HG treated with glibenclamide and atorvastatin } & Mean \pm SD & $118.25 \pm 8.65^{c}$ \\
\hline & $\%$ Change to control & 25.46 \\
\hline & $\%$ of improvement & 179.57 \\
\hline
\end{tabular}

Glucose is expressed as $\mathrm{mg} / \mathrm{dl}$ and $\alpha$-amylase is expressed as $\mathrm{U} / \mathrm{l}$. Data presented as mean $\pm \mathrm{SD}, \mathrm{n}=10$. Statistical analysis is carried out using Co-state and SPSS computer programs (version 8), where unshared letter is significant at $\mathrm{p} \leq 0.05$. SD: Standard deviation, HC-HG: Hypercholesterolemia-Hyperglycemia, S. tomentosa: Sophora tomentosa, I. tricolor: Ipomoea tricolor

Table 2: Comparative effects of I. tricolor and S. tomentosa supplementation on liver function in control and different therapeutic groups

\begin{tabular}{|c|c|c|c|c|c|}
\hline Groups & Parameters & $\operatorname{AST}(\mathrm{U} / \mathrm{L})$ & $\operatorname{ALT}(\mathrm{U} / \mathrm{L})$ & $\operatorname{ALP}(\mathrm{U} / \mathrm{L})$ & LDH (U/L) \\
\hline Negative control & Mean \pm SD & $98.5 \pm 2.88^{b}$ & $15.25 \pm 0.64^{c}$ & $147.25 \pm 8.77^{c}$ & $26875 \pm 853.911^{\mathrm{a}}$ \\
\hline \multirow[t]{2}{*}{ Negative treated with $I$. tricolor } & Mean \pm SD & $95 \pm 5.77^{b}$ & $16.75 \pm 0.95^{c}$ & $152.5 \pm 9.57^{c}$ & $25725 \pm 1871.49 .911^{\mathrm{a}}$ \\
\hline & $\%$ Change to control & +3.55 & +9.83 & +3.56 & 4.27 \\
\hline \multirow[t]{2}{*}{ Negative treated with $S$. tomentosa } & Mean \pm SD & $97.83 \pm 5.34^{\mathrm{b}}$ & $17.83 \pm 1.9^{c}$ & $142.50 \pm 10.54^{c}$ & $26975 \pm 1391.34^{\mathrm{a}}$ \\
\hline & $\%$ Change to control & +0.68 & +16.91 & -1.18 & 0.37 \\
\hline \multirow[t]{2}{*}{$\mathrm{HC}-\mathrm{HG}$} & Mean \pm SD & $226.33 \pm 13.05^{\mathrm{a}}$ & $39.00 \pm 3.8^{\mathrm{a}}$ & $321 \pm 28.72^{\mathrm{a}}$ & $11625.00 \pm 1108.67^{b}$ \\
\hline & $\%$ Change to control & +129.77 & +155.73 & +117.99 & 56.74 \\
\hline \multirow{2}{*}{ HC-HG treated with I. tricolor } & $\%$ Change to control & -8.975 & +57.90 & +32.42 & 4.18 \\
\hline & $\%$ of improvement & 138.75 & 97.83 & 85.56 & 52.55 \\
\hline \multirow[t]{3}{*}{ HC-HG treated with $S$. tomentosa } & Mean \pm SD & $92.33 \pm 2.86^{\mathrm{b}}$ & $18.66 \pm 0.94^{c}$ & $158.16 \pm 15.91^{c}$ & $24850 \pm 2834.90^{\mathrm{a}}$ \\
\hline & $\%$ Change to control & -6.26 & +22.36 & +7.409 & 7.53 \\
\hline & $\%$ of improvement & 136.04 & -133.37 & 110.58 & 49.20 \\
\hline \multirow{3}{*}{$\begin{array}{l}\text { HC-HG treated with glibenclamide } \\
\text { and atorvastatin }\end{array}$} & Mean \pm SD & $105.00 \pm 4.08^{b}$ & $26.00 \pm 4.32^{b}$ & $190.75 \pm 9.42^{b}$ & $24900 \pm 2404.20^{\mathrm{a}}$ \\
\hline & $\%$ Change to control & +6.59 & +204.76 & +29.54 & 7.34 \\
\hline & $\%$ of improvement & 123.17 & 85.24 & 88.45 & 49.39 \\
\hline
\end{tabular}

Liver enzyme activities and LDH are expressed in U/L. Data presented as mean \pm SD, $n=10$. Statistical analysis is carried out using Co-state and SPSS computer programs (version 8), where unshared letter is significant at $\mathrm{p} \leq 0.05$. SD: Standard deviation, HC-HG: Hypercholesterolemia-Hyperglycemia, S. tomentosa: Sophora tomentosa, I. tricolor: Ipomoea tricolor, ALT: Alanine aminotransferases, AST: Aspartate aminotransferases, ALT: Alkaline phosphatase, LDH: Lactate dehydrogenase 
quality and/or quantity of the $\beta$-cells in the pancreas by enhancing regeneration of these cells. Furthermore, the mechanism underlying the reported therapeutic activity may involve, at least, an improvement of insulin sensitivity which can lead to an increase in peripheral glucose utilization [26]. Another possible action site for both extracts to exert there hypoglycemic effect is in the gastrointestinal tract; the fiber of plants may also interfere with carbohydrate absorption; thus affecting blood glucose, by slowing the digestion of food and decreasing the rate of carbohydrate absorption and clearing the postprandial glucose load [27]. Therefore, the hypoglycemic activity of this extracts may be due to inhibition of hepatic glucose production and/or stimulation of glucose utilization by peripheral tissues, especially muscle and adipose tissues [28]. In addition, both extracts could also act as inhibitors of tubular renal glucose reabsorption.

\section{The hepatic ameliorative effect of $I$. tricolor and $S$. tomentosa}

The hepatic ameliorative effect of I. tricolor and S. tomentosa revealed that serum ALT, AST, and ALP enzyme activities were significantly elevated in high cholesterol and glucose-induced rats as compared to normal rats. The serum concentrations of ALT, AST, and ALP activities were found to determine the functionality and cellular membranes integrity of the liver $[29,30]$. The elevated enzyme activities in serum of HC-HG rats reflect the alterations in serum membrane integrity and/or permeability leak of these enzymes into the serum [31-33] ALP is located in the biliary duct of the liver, obstruction of this duct was found to elevate the level of the enzyme in the circulation $[29,30]$. In consistent with the present results [32-34], found that; the activities of ALT and AST tend to increase according to the exogenous cholesterol contents from diet and that HC state significantly stimulate ALT and AST enzyme activities in the serum, resulting in increased enzyme leakage from hepatocytes. Excessive storage of fat in the liver affects liver functions and increases the susceptibility to free radical attack in HC-HG rats resulting in liver damage. The increases in the serum activities of these enzymes were found to be directly proportional to the degree of cellular damage as described by Yadav et al. [35]. However, Noori et al. [31] added that the increase in aminotransferases may be due to the cellular damage in the liver caused by STZ-induced diabetes. In agreement with the present results, Ahmed et al. [29] and Munish and Chanchal [36] found high enzyme concentrations of ALP and ALT in diabetic animals. It's well known that ALP enzyme originates predominately from the liver and from bone. Persistently elevated ALP levels in the liver may indicate chronic cholestasis or infiltrative liver disease. The reduction in LDH enzyme activity in the HC-HG rats In good agreement with El Baz et al. [19], who noticed reduction in LDH enzyme activity in diabetic rats due to the perturbation in membrane permeability leading to leakage of the enzyme to the circulation.

On the other hand, the treatment of HG-HC rats with I. tricolor and S. tomentosa extracts ameliorated the structural and functional integrity of the liver membrane and pancreas as evident by the significant reduction in the elevated levels of these serum marker enzymes and amelioration in pancreas and liver architectures in HG-HC treated rats as compared to the positive control rats. The declined enzyme activities secondary to drug and the extract treatments might be ascribed to their ability to maintain membrane integrity thereby restricting the leakage of these enzymes $[37,38]$. Thus, the enhancement in enzyme activities resulting from extracts supplementation may help in preventing oxidative damage by detoxifying ROS; that in turn, reduce hyperlipidemia. Thus, it is expected that both treatments are effective for the recovery of the hepatic function by restoring lipid metabolism that subsequently delays the hepatic disorders.

The ameliorative effects of both extracts in diabetic rats may be explained on the basis of Munish and Chanchal [36] study, that the hypoglycemic activity and the reducing effect on biochemical profile; ALP, AST, and ALT with certain Phyllanthus extracts on biochemical profile (renal, liver and cardiovascular complications) in case of alloxan-induced diabetic rats may be attributed to the presence of phenolic compounds. Most of the bioactive compounds (especially flavonoids and triterpenoids) showed a mechanism to improve the liver and pancreas cells functions and hence normalized liver enzymes [39].

Genus of Sophora and Ipomoea are a prolific source of structurally diverse bioactive metabolites with interesting activities [5,40]. The chemical review on Sophora tomentosa reveals that the presence of alkaloids, polysaccharides, isoprenylated flavonoids, isoflavonones, flavones, flavonols, their glycosides, and these compounds have been previously reported to have wide bioactivity including anti-diabetic, antioxidant, hepatoprotective and immune regulatory $[5,6]$. Recently, it was found that the ethyl acetate extract of roots of $S$. flavescens significantly controlled levels of insulin, through stimulation of GLUT4 which attenuated by AMP-activated protein kinase pathway and this extract was practically non-toxic for mice.

Many phytochemical studies [40] declared that Ipomoea contains many bioactive secondary metabolites which having promising effects in ameliorating different disorders such as anti-nociceptive, anti-oxidative, and anti-inflammatory effects. Several phenolic compounds, namely, phenolic acids, flavonoids, organic acids, and anthocyanins $[41,42]$ have been described in several Ipomoea species. It was reported that the isolated anthocyanins decreased atherosclerosis progress, ameliorated oxidative status and endothelial dysfunction in mice [42], and also may act as antioxidants [40-42].

Thus, the ameliorative effect of both extracts may be related to the secondary metabolites content representing in phenolic compounds as flavonoids, tannins, and anthocyanins. The mechanism of hepatoprotective and the amelioration of hepatic and pancreatic issues ability of extracts may be attributed to numerous bioactive compounds such as isoprenylated flavonoids, terpenoids, flavonoids, alkaloids, and polysaccharides. Hepatotoxic constituents of $S$. flavescens were determined to be prenylated flavanones, kurarinone, and sophora flavanone [42]. Oxymatrine, a quinolizidine alkaloid, has been widely used for the treatment of hepatitis. A study displayed that oxymatrine can alleviate HG and hyperlipemia in a high-fat diet and STZ-induced diabetic rats might by improving insulin secretion and sensitivity $[43,44]$.

\section{The antioxidant effect of $\boldsymbol{I}$. tricolor and $\boldsymbol{S}$. tomentosa}

It is oblivious from Table 3 that, normal control rats treated with I. tricolor and S. tomentosa extracts, showed insignificant change in the levels of NO, GSH and MDA as compared to normal control rats Diabetic rats recorded a significant increase in MDA and NO levels by 14.65 and $23.86 \%$, respectively. While significant reduction in GSH level $(17.45 \%)$ was detected. The treatment of HC-HG rats with I. tricolor and $S$. tomentosa extracts as well as drugs showed significant reduction in GSH level with percentages of improvement $38.91 \%, 47.64 \%$ and $43.86 \%$, respectively. In addition, HC-HG rats treated with I. tricolor and standard drugs declared insignificant change in lipid peroxide level with amelioration percentages $112.37 \%$ and $113.02 \%$, respectively. However, a significant increase was recorded in lipid peroxide level on treatment HC-HG rats with $S$. tomentosa with amelioration percentage $89.57 \%$. Furthermore, NO showed insignificant change with percentages of amelioration $118.89 \%$ and $118.95 \%$, respectively, while the treatment of HC-HG rats with S. tomentosa extract demonstrated significant increase with amelioration percent 109.14\% (Table 3).

As compared to control group, $\mathrm{HC}-\mathrm{HG}$ rats recorded significant decrease in GSH level by $56.36 \%$. However, MDA and NO showed dramatic elevation of $127.03 \%$ and $142.76 \%$, thus HC-HG induced oxidative stress resulted in elevation in hepatic MDA and NO, and in contrast a decline in hepatic GSH level, the non-enzymatic antioxidant defense system. The present results are in accordance to the work done by Prasad et al. [45], who showed that diet-induced HC and STZ-induced rats produces oxidative stress in the myocardium. The induced oxidative damage has been demonstrated by the increased lipid peroxidation and inhibition of enzymes required to prevent such oxidative damage and liver GSH concentration $[45,46]$. As they observed a significant elevation of 
Table 3: Comparative effects of $I$. tricolor and $S$. tomentosa supplementation on antioxidant markers in control and different therapeutic groups

\begin{tabular}{|c|c|c|c|c|}
\hline Groups & Parameters & GSH & MDA & NO \\
\hline Negative control & Mean \pm SD & $106 \pm 4.54^{\mathrm{b}}$ & $0.307 \pm 0.059^{c}$ & $16.30 \pm 0.36^{\mathrm{cd}}$ \\
\hline \multirow[t]{2}{*}{ Negative treated with I. tricolor } & Mean \pm SD & $129.25 \pm 7.8^{\mathrm{a}}$ & $0.345 \pm 0.012^{\mathrm{bc}}$ & $14.37 \pm 0.28^{\mathrm{d}}$ \\
\hline & $\%$ Change to control & +21.93 & +12.37 & -11.84 \\
\hline \multirow[t]{2}{*}{ Negative treated with $S$. tomentosa } & Mean \pm SD & $131 \pm 2.75^{\mathrm{a}}$ & $0.367 \pm 0.026^{b c}$ & $15.62 \pm 0.42^{\mathrm{d}}$ \\
\hline & $\%$ Change to control & +23.58 & +19.54 & -4.17 \\
\hline \multirow[t]{2}{*}{ HC-HG } & Mean \pm SD & $46.25 \pm 3.86^{\mathrm{d}}$ & $0.697 \pm 0.05^{\mathrm{a}}$ & $39.57 \pm 3.90^{\mathrm{a}}$ \\
\hline & $\%$ Change to control & -56.36 & +127.03 & +142.76 \\
\hline \multirow{2}{*}{ HC-HG treated with I. tricolor } & $\%$ Change to control & -17.45 & +14.65 & +23.86 \\
\hline & $\%$ of improvement & 38.91 & -112.37 & -118.89 \\
\hline \multirow[t]{3}{*}{ HC-HG treated with S. tomentosa } & Mean \pm SD & $96.75 \pm 6.02^{\mathrm{c}}$ & $0.422 \pm 0.25^{\mathrm{b}}$ & $21.78 \pm 0.53^{\mathrm{b}}$ \\
\hline & $\%$ Change to control & -8.72 & +37.45 & +33.61 \\
\hline & $\%$ of improvement & 47.64 & -89.57 & -109.14 \\
\hline \multirow{3}{*}{ HC-HG treated with glibenclamide and atorvastatin } & Mean \pm SD & $92.75 \pm 10.04^{c}$ & $0.35 \pm 0.026^{\mathrm{bc}}$ & $20.18 \pm 4.08^{b c}$ \\
\hline & $\%$ Change to control & -12.5 & -14.00 & +23.80 \\
\hline & $\%$ of improvement & 43.86 & -113.02 & -118.95 \\
\hline
\end{tabular}

GSH is expressed in $\mathrm{mmol} / \mathrm{L}, \mathrm{MDA}$ is expressed in $\eta \mathrm{mol} / \mathrm{mL}$ and NO is expressed in $\mu \mathrm{mol} / \mathrm{mL}$. Data presented as mean $\pm \mathrm{SD}, \mathrm{n}=10$. Statistical analysis is carried out using Co-state and SPSS computer programs (version 7), where unshared letter is significant at p $\leq 0.05$. SD: Standard deviation, HC-HG: Hypercholesterolemia-Hyperglycemia, S. tomentosa: Sophora tomentosa, I. tricolor: Ipomoea tricolor, MDA: Malondialdehyde, GSH: Glutathione, NO: Nitric oxide

hepatic thiobarbituric acid reactive substances concentration in rats fed a high cholesterol diet as compared to normal control rats.

NO at physiological levels may play an important role in the maintenance of vascular homeostasis, while NO produced under oxidative stress conditions may evoke specific tissue injury. Serum NO level may also increase during various pathological conditions, as inflammation, sepsis and stroke are associated with NO overproduction [47]. Oxygen radicals exert their cytotoxic effects, in part, by causing peroxidation of membrane lipids, which results in increased membrane permeability and the loss of membrane integrity. Increased cholesterol levels enhance the production of ROS and provoke cellular injury [48]. This study declared significant increase in the level of NO $(142.76 \%)$ in the cholesterol-diabetic stressed rats in comparison to controls. This increase in NO level might be attributed to HC-HG induced oxidative stress. The results clearly showed the increasing NO level might be via apoptosis [49]. These results were documented by the present findings of hepatocyte degeneration and disarrangement changes in pancreatic blood vessels and interlobular duct. In good agreement with the present result, ElBaz et al. [50,51] declared that free radicals act by lipid peroxidation leads to release of MDA in a large amount. Thus, MDA concentration in the organs liver and plasma can inform about the level of cell damage and apoptosis in diabetic patients and/or animals, which in turn effect on the liver and pancreatic tissue showing marked hepatocyte ballooning and hydropic degeneration as well as disarrangement changes in pancreatic blood vessels and interlobular duct $[48,50,51]$. In DM, the high levels of glucose (HG) are a known reason for enhancing the elevated levels of plasma free radical $[50,51]$.

GSH is one of the most abundant non-enzymatic antioxidant biomolecules present in tissues which can alter the diabetic effects via scavenging free radicals or preventing their conversion to toxic products or provision of a substrate for glutathione peroxidase and glutathione S-transferase [52-54].

I. tricolor and S. tomentosa extract treatments to stressed rats showed marked surge in GSH concentration with the percentage of improvements $38.91 \%, 47.64 \%$ and $43.86 \%$, respectively, for I. tricolor and $S$. tomentosa extracts and drugs. While, MDA achieved significant decrease by $112.37,89.57$ and $113.02 \%$, respectively, for I. tricolor and $S$. tomentosa as well as atorvastatin-glibenclamide reference drugs, in comparison with normal as well as positive control rats.

Treatment of HC-HG rats with $I$. tricolor and S. tomentosa extracts and standard drugs showed insignificant change in NO as compared to untreated rats and normal control group, with percentages of amelioration reached to $118.89 \%, 109.14 \%$ and $118.95 \%$, respectively, for I. tricolor and S. tomentosa and reference drugs. In agreement with the current results, Pavana et al. [52] explained the mode of depressing nitrite formation by the competition action of plant extracts Tephrosia purpurea with oxygen in the reaction with $\mathrm{NO}$ and other nitrogen oxides such as $\mathrm{NO}_{3}$, and $\mathrm{N}_{2} \mathrm{O}_{3}$. The increased oxidized GSH levels in HC-HG rats can be attributed to spontaneous non-enzymatic GSH oxidation as suggested by Meister and Anderson [55]. GSH in cholesterol- glucose stressed rats decreased significantly $(56.36 \%)$ as compared to the normal ones. These reductions may be due to the increased utilization of these anti-oxidants for quenching free radicals produced during HC-HG condition. In parallel results, Qi et al. [56] found that atorvastatin and glibenclamide treatment to $\mathrm{HC}-\mathrm{HG}$ rats enhanced the concentration of liver GSH and attributed this to the ability of drugs to improve the defensive nature of liver against free radicals which in turn preserved liver and pancreas architectures. Thus, the same could be applicable to $I$. tricolor and S. tomentosa extracts which in turn ameliorate liver and pancreas architectures. Hence, it could be concluded that I. tricolor and $S$. tomentosa showed antihyperlipidemic and anti-HG activities which need further clinical research to using as a promising candidate nutraceuticals.

\section{The hypolipidemic effect of $I$. tricolor and $S$. tomentosa}

Data manipulated in Table 4 clearly indicated insignificant difference in lipid profile in healthy control rats treated with $I$. tricolor and S. tomentosa extracts as compared to normal control rats. HC-HG rats showed significant elevation in TG $(183.71 \%)$, TC $(113.76 \%)$, and LDL-C $(102.46 \%)$ while a significant reduction in HDL-C was detected (97.39\%), comparing to control rats. The oral supplementation of $I$. tricolor extract and reference drug to $\mathrm{HC}-\mathrm{HG}$ rats resulted in insignificant change in TC, HDL-C and TG with amelioration percentages $127.48 \%, 131.13 \%$ and $181.96 \%$, respectively. Although, LDL-C level recorded significant increase with percentage of improvement $68.13 \%$. In addition, the treatment of diabetic rats with $S$. tomentosa exhibited insignificant change in TC, HDL-C and TG with percentages of amelioration $105.60 \%, 84.90 \%$ and $147.27 \%$, respectively, while LDL-C demonstrated significant increase with the percentage of improvement $83.79 \%$. Regarding reference drugs, the percentages of amelioration in TC, LDL-C, HDL-C and TG reached to $87.94 \%, 81.02 \%, 64.78 \%$ and $188.21 \%$, respectively (Table 4 )

\section{Histopathological investigation}

Histopathological investigation of liver tissue revealed normal structure of hepatic cells and no observed changes in normal rats treated with $I$. 
Table 4: Comparative effects of $I$. tricolor and $S$. tomentosa supplementation on lipid profile in control and different therapeutic groups

\begin{tabular}{|c|c|c|c|c|c|}
\hline Groups & Parameters & TC & LDL-C & HDL-C & TG \\
\hline Negative control & Mean \pm SD & $92.00 \pm 2.44^{\mathrm{b}}$ & $16.60 \pm 1.02^{\mathrm{d}}$ & $53.25 \pm 6.18^{c}$ & $85.5 \pm 3.10^{\mathrm{b}}$ \\
\hline \multirow[t]{2}{*}{ Negative treated with I. tricolor } & Mean \pm SD & $87.50 \pm 6.45^{b}$ & $16.80 \pm 0.22^{\mathrm{d}}$ & $47.25 \pm 3.20^{c}$ & $79 \pm 13.11^{\mathrm{b}}$ \\
\hline & $\%$ Change to control & -4.89 & +1.20 & -11.26 & -7.60 \\
\hline \multirow[t]{2}{*}{ Negative treated with S. tomentosa } & Mean \pm SD & $85.75 \pm 7.88^{b}$ & $17.33 \pm 1.70^{\mathrm{d}}$ & $47.91 \pm 3.68^{b}$ & $82 \pm 3.55^{b}$ \\
\hline & $\%$ Change to control & -6.79 & +4.39 & -10.028 & -4.093 \\
\hline \multirow[t]{2}{*}{ HC-HG } & Mean \pm SD & $196.66 \pm 53.28^{\mathrm{a}}$ & $33.61 \pm 0.89^{a}$ & $22.33 \pm 2.30^{\mathrm{a}}$ & $242.58 \pm 82.19^{a}$ \\
\hline & $\%$ Change to control & +113.76 & +102.46 & -97.39 & +183.71 \\
\hline \multirow{2}{*}{ HC-HG treated with I. tricolor } & $\%$ Change to control & -13.72 & +34.96 & -18.30 & +1.75 \\
\hline & $\%$ of improvement & -127.48 & -68.13 & -131.13 & -181.96 \\
\hline \multirow[t]{3}{*}{ HC-HG treated with S. tomentosa } & Mean \pm SD & $99.50 \pm 7.37^{b}$ & $19.70 \pm 1.73^{c}$ & $68.12 \pm 8.00^{c}$ & $116.66 \pm 36.70^{b}$ \\
\hline & $\%$ Change to control & +8.52 & +20.85 & +27.92 & +36.44 \\
\hline & $\%$ of improvement & -105.60 & -83.79 & -84.90 & -147.27 \\
\hline \multirow[t]{3}{*}{ HC-HG treated with glibenclamide and atorvastatin } & Mean \pm SD & $115.75 \pm 18.94^{b}$ & $20.16 \pm 1.34^{c}$ & $78.83 \pm 9.65^{b}$ & $81.66 \pm 6.59^{\mathrm{b}}$ \\
\hline & $\%$ Change to control & +25.81 & +21.44 & +48.03 & -4.49 \\
\hline & $\%$ of improvement & -87.94 & -81.02 & -64.78 & -188.21 \\
\hline
\end{tabular}

TC, LDL-C, HDL-C and TG are expressed in $\mathrm{mg} / \mathrm{dL}$. Data presented as mean $\pm \mathrm{SD}, \mathrm{n}=10$. Statistical analysis is carried out using Co-state and SPSS computer programs (version 7), where unshared letter is significant at $\mathrm{p} \leq 0.05$. SD: Standard deviation, HC-HG: Hypercholesterolemia-Hyperglycemia, S. tomentosa: Sophora tomentosa, I. tricolor: Ipomoea tricolor, TC: Total cholesterol, TG: Triacylglycerol, HDL-C: High-density lipoprotein-cholesterol, LDL-C: Low-density lipoprotein-cholesterol

tricolor and S. tomentosa (Fig. 1c and b) as compared to normal untreated control rats (Fig. 1a). However, HC-HG rats exhibited congestion in portal vessels and sinusoids with mild centrilobular hepatocyte degeneration (Fig. 1d), moderate to marked hepatocyte ballooning (black arrow), and hydropic degeneration (Fig. 1e). While HC-HG rats treated with S. tomentosa showed normal lobular hepatic architecture (Fig. 1f). In addition, HC-HG rats treated with I. tricolor declared nearly normal hepatic cells with mild sinusoidal dilatation and congestion (Fig. 1g). Furthermore, HC-HG rats treated with reference drug exhibited normal hepatic architecture with arranged hepatocyte (Fig. 1h). In addition, treatment of control rats with I. tricolor and S. tomentosa showed no changes in Islets of Langerhans (Fig. $2 \mathrm{~b}$ and c) as compared to normal untreated control rats (Fig. 2a). HC-HG rats showed disarrangement changes in pancreatic blood vessels and interlobular duct (Fig. 2d) and disordered in acini (exocrine duct) (Fig. 2e). However, pancreatic tissue of HC-HG rats treated with I. tricolor and S. tomentosa as well as standard drug showed enhancement in Langerhans cells (Fig. 2f-h). An image recognition system was built to extract data from these tissues photographed liver and pancreas tissues Images [57].

This study shows that the cholesterol-enriched diet for 12-week resulted in a dramatic surge in serum total cholesterol (81.83\%), total lipids (63.74\%), and TGs (176.30\%). Concerning lipoproteins, it was obvious that circulating serum HDL-C level was significantly diminished $(85.74 \%)$ in the cholesterol-stressed rats, whereas atherogenic lipoproteins; LDL-C level was significantly raised as compared to normal control group, thus providing a model for dietary hyperlipidemia. The increase of lipid parameters had been shown to be a strong risk factor for coronary heart diseases (CHD) in many populations $[51,58]$. These results run in parallel with Rizk et al. [32,33]. People with higher levels of HDL-C seem to protect from coronary vascular diseases as HDL-C act as antioxidant and protect LDL-C from oxidation so reduce LDL-C from circulation [58].

In diabetic complications, besides the abnormality in glucose metabolism, DM often includes another metabolic disorder that is abnormality in lipid metabolism [59]. Under normal condition, insulin activates lipoprotein lipase (LPL) which hydrolyzes triglycerides. Insulin deficiency results in failure to activate the LPL enzyme, thereby causing hypertriglyceridemia [60]. On the other hand, in insulin deficient, the plasma free fatty acids concentration is elevated as a result of increased free fatty acids outflow from fat depots, where the balance of the free fatty acids esterification, triglycerides lipolysis is displaced in favor of lipolysis $[32,33,60]$. Moreover, HC and hypertriglyceridemia are often associated with DM and this increment may be explained on the basis of STZ-induced diabetes; there is excess of fatty acids in the serum, which promotes conversion of excess fatty acids into phospholipids and cholesterol in the liver. The significant elevation in lipid profile in serum of HC-HG rats was achieved also by Hristova and Aloe [61] and Borai et al. [2], who attributed hyperlipidemia in DM to elevated level of cortisol, which has an important role in the process of fat accumulation as cortisol promotes the liberation of free fatty acids from adipose tissue into blood stream by inducing and maintaining the synthesis of the hormone sensitive lipase, thus increasing free fatty acids level which contributes to cardio-vascular risk.

It was noticed that HC-diet raises hepatic cholesterol content resulting in the increase of TG synthesis. The cholesterol biosynthesis is controlled by the rate limiting enzyme, HMG-CoA reductase. Statin blocks this enzyme and thereby prevents cholesterol biosynthesis [51,62]. In this study, the cholesterol lowering effects of statin (mainly LDL-C) can be attributed to HMG-CoA reductase inhibition.

The present results show $97.39 \%$ increase in serum TC level of HC-HG rats, which is comparable with that reported by Borai et al. [2], who feed rats cholesterol $(0.3 \%)$ diet with the addition of bile acids $(0.5 \%)$ and showed 1.7-fold higher total cholesterol in their cholesterol-fed rats than normal rats. In consistent with this study, Jang et al. [63] attributed the effect of $\mathrm{HC}$ to the increased dietary cholesterol intake that subsequently increased the rate of intestinal cholesterol absorption. Furthermore, lard fat is rich in saturated fatty acids, known to increase serum LDL-C and monounsaturated fatty acids, which can increase serum TG [2].

Moreover, in parallel results Cohen et al. [64], found that cholesterolenriched diet resulted in a significant increase in total cholesterol, total lipids, phospholipids and TG in serum and liver and these elevated parameters were associated with increased serum LDL-c level and decreased circulating HDL-C, thus providing a model for dietary hyperlipidemia.

The present results demonstrate, significantly increase in LDL-C in HC-HG rats, while, significantly lower levels of them were detected in I. tricolor and S. tomentosa treated rats. The high level of LDL-C found in HC-HG rats may be attributed to a down-regulation in LDL-C receptors by cholesterol and saturated fatty acids included in the diet [65]. In contrast, reduction in HDL-C (97.39) following cholesterol feeding may be due to contributed acceleration of apolipoprotein A-I (apoA-I) clearance from the serum based on cholesterol-enriched diets. HDL-C binds to arterial and transports it to the liver for metabolisms $[30,66]$. 

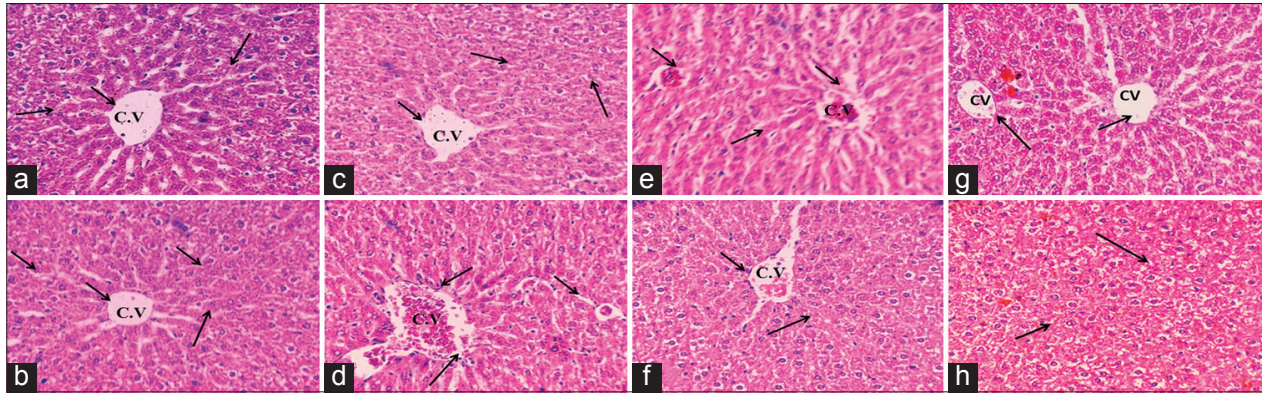

Fig. 1: (a) Control liver section, stained with $\mathrm{H}$ and $\mathrm{E}, \times \mathbf{2 0 0}$ showed normal structure of hepatic cells. (b) Liver section of control rats treated with Sophora tomentosa showed no observed changes in hepatic cells ( $\mathrm{H}$ and E, $\times 200)$. (c) Of liver section of control rats treated with Ipomoea tricolor showed no change in hepatic cells with respect to control group, (d) liver section of hypercholesterolemiahyperglycemia (HC-HG) showed congestion in portal vessels and sinusoids with mild centrilobular hepatocyte degeneration stained with $\mathrm{H}$ and $\mathrm{E}, \times \mathbf{2 0 0}$. (e) Of liver section of HC-HG rats showed preserved (intact) lobular hepatic architecture, moderate to marked hepatocyte

ballooning (black arrow), and hydropic degeneration. (f) Demonstrated liver section of HC-HG treated rats with $S$. tomentosa showed normal lobular hepatic architecture (H and E, $\times 200)$. (g) Of liver section HC-HG treated with I. tricolor showed nearly normal hepatic cells with mild sinusoidal dilatation and congestion. (h) Of HC-HG liver treated with reference drug showed normal hepatic architecture with arranged hepatocyte

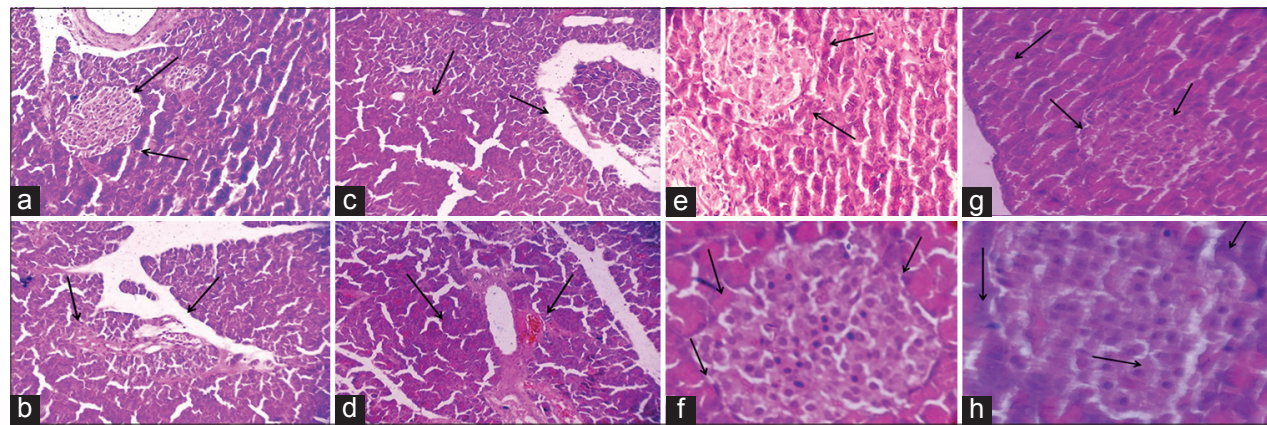

Fig. 2: (a) Histological organization of the pancreas of control rats $\times 200$. (b) Of pancreas of control rats treated with Ipomoea tricolor and Sophora tomentosa showed no change in Islets of Langerhans $\times 200$ stained with $\mathrm{H}$ and E. (c) Of the pancreas of control rats treated with I. tricolor, (d) No histopathological change. (d) Of pancreas tissue section of hypercholesterolemia-hyperglycemia (HC-HG) rats showing disarrangement changes in pancreatic blood vessels and interlobular duct $\times 200$ ( $H$ and $E$ ). (e) Histological section of the pancreas of HC-HG rats revealed disordered in acini (exocrine duct), $\times 200$. (f) Of pancreatic tissue section of HC-HG rats treated with I. tricolor and

$S$. tomentosa showed enhancement in Langerhans cells $(\mathrm{H}$ and $\mathrm{E}) \times 200$. $(\mathrm{g})$ Histological section of the pancreas of $\mathrm{HC}-\mathrm{HG}$ rats $\times 200$ treated with I. tricolor showing restore most of pancreatic histology. (h) Of pancreas tissue section of HC-HG rats treated with standard drug showing enhanced in pancreatic cells, stained with $(\mathrm{H}$ and $\mathrm{E}) \times 200$

The treatment of cholesterol-stressed rats with I. tricolor and $S$. tomentosa extracts induced marked significant decrease of serum total lipids, total cholesterol, TG and LDL-c concentrations as compared to the positive control HC-HG rats. Rats treated with both extracts showed enhanced HDL-C level $(131.13 \%$ and $84.90 \%$ for I. tricolor and S. tomentosa, respectively); which may be due to the ability of the extract to hasten the decomposition of free radical species generated during cholesterol administration; this corroborates the report of a previous study of Aly et al. [67] who explained that due to inhibition of lipogenic enzymes as LPL [2] Moreover, this hypolipidemic effect of extracts might be due todietary fibers which are known to interfere with cholesterol absorption and enter to hepatic bile circulation, resulting in depletion of hepatic cholesterol pools and reducing TAG levels by inhibition of hepatic lipogenesis [2].

The mechanism, by which extracts reduce serum lipoprotein levels in HC-HG rats, may be through the inhibition of 3-hydroxy-3methylglutaryl coenzyme A reductase, the rate-limiting enzyme of cholesterol biosynthesis [68]. Both extracts produced a significantly lower serum TG level, another well-established and recognized risk factor for developing atherosclerosis [69]. Thus, the significantly lower serum total cholesterol levels produced by the extract indicates the ability of the extract to protect against cardiovascular diseases (CVDs). In addition, the decreased serum TG concentration in HC-HG rats treated with extracts may be explained on the basis of increased clearance of TG secondary to increased activity of LPL [70].

The low atherogenic indices are seemed to be protective against CHD, and the high HDL-C levels could potential contribute to its antiatherogenic properties including its capacity to inhibit LDL-C oxidation and protect endothelial cells from the cytotoxic effects of oxidized LDL-C [71]; thus, these treatments provides us with a good indicator of reducing atherogenicity, which leads in consequence to a decreased possibility of CVD occurrence.

Significant reductions of serum TC and LDL-C concentrations and elevations of daily bile acid excretion in I. tricolor and S. tomentosa treated rats suggested the mechanism of cholesterol breakdown into bile acid, by which both-extracts effectively lowered serum cholesterol levels. When diet supplemented with I. tricolor and S. tomentosa extracts was consumed, other nutritional components were digested and absorbed from the small intestine and extracts became a major component in the gut lumen. LDL-C was removed from blood and converted into bile acids by the liver to replace the bile acids lost in the stool, consequently, serum LDL-C was also decreased simultaneously [72]. Furthermore, the reductions in lipid levels may be due to the increased fecal lipid excretion. Thus, the reduced absorption of cholesterol and fat is an important hypolipidemic action of extracts. This result might suggest that both extracts can effectively prevent HC-HG and longer treatment 
was better in terms of its $\mathrm{HC}-\mathrm{HG}$ effect. It is possible the beneficial effects of I. tricolor and S. tomentosa extracts may lead to the development of nutraceuticals agent. This finding is in agreement with Makni et al. [58], who stated that an increase in the HDL-C is one of the most important criteria for ananti-HC agent. Furthermore, the anti-hyperlipidemic- HG activities of $I$. tricolor and $S$. tomentosa extracts may be attributed to an important relationship between the anti-hyperlipidemic effect and the antioxidant activities of both extracts [73]. Besides, the correction of insulin level induced by plants causing a regulation of carbohydrate and lipids metabolism by inhibition of lipolysis through inhibition of hormone-sensitive lipases activity in adipose tissue and suppresses the release of free fatty acids causing stimulation of lipogenesis [74].

\section{CONCLUSION}

The present research in bioinformatics focuses on pharmacological effects of extract of $I$. tricolor and $S$. tomentosa on some biochemical parameters in high fat diet-induced HC and STZ-induced HG in rats compared to atorvastatin. Repairing effect of $I$. tricolor and S. tomentosa on liver injury and oxidative damage in HC-HG induced rats is clearly revealed. Hence, it could be concluded that I. tricolor and S. tomentosa exhibited antihyperlipidemic and anti-HG activities with more or less similar effect which need more further clinical research to using as a promising candidate nutraceuticals. In the future, we need a new approach to be applied to the problem of classifying biochemical parameters according to pharmacological effects of natural extracts. Therefore extracting meaningful, accurate knowledge about this problem could provide an insight into the behavior of drugs when binding to the recognition of injured tissues that could assist drug designers.

\section{REFERENCES}

1. Keedwell E, Narayanan A. Intelligent Bioinformatics. Chichester, England: John Wiley \& Sons, Ltd; 2005.

2. Borai IH, Ezz MK, Rizk MZ, El-Sherbiny M, Matloub AA, Aly HF, et al. Hypolipidemic and anti-atherogenic effect of sulphated polysaccharides from the freen alga Ulvafasciata. Int J Pharm Sci Rev Res 2015;31(1):1-12.

3. Liang YT, Wong WT, Guan L, Tian XY, Ma KY, Huang Y, et al. Effect of phytosterols and their oxidation products on lipoprotein profiles and vascular function in hamster fed a high cholesterol diet. Atherosclerosis 2011;219(1):124-33.

4. Tziomalos $\mathrm{K}$, Athyros VG, Karagiannis A, Mikhailidis DP Management of statin-intolerant high-risk patients. Curr Vasc Pharmacol 2010;8(5):632-7.

5. Krishna PM, Rao KN, Sandhya S, Banji D. A review on phytochemical, ethno medical and pharmacological studies on genus Sophora, Fabaceae. J Rev Bras Farm 2012;22(5):1145-54.

6. Yang X, Yang J, Xu C, Huang M, Zhou Q, Lv J, et al. Antidiabetic effects of flavonoids from Sophora flavescens EtOAc extract in Type 2 diabetic KK-ay mice. J Ethnopharmacol 2015;171:161-70.

7. Adaramoye OA, Akintayo O, Achem J, Fafunso MA. Lipid-lowering effects of methanolic extract of Vernonia amygdalina leaves in rats fed on high cholesterol diet. Vasc Health Risk Manag 2008;4(1):235-41.

8. Milani E, Nikfar S, Khorasani R, Zamani MJ, Abdollahi M. Reduction of diabetes-induced oxidative stress by phosphodiesterase inhibitors in rats. Comp Biochem Physiol C Toxicol Pharmacol 2005;140(2):251-5.

9. Shalaby NM, Abd-Alla HI, Aly HF, Albalawy MA, Shaker KH, Bouajila J. Preliminary in vitro and in vivo evaluation of anti-diabetic activity of Ducrosia anethifolia Boiss. And its linear furanocoumarins. J BioMed Res Int 2014;2014:1-13.

10. Dachicourt N, Bailbé D, Gangnerau MN, Serradas P, Ravel D, Portha B. Effect of gliclazide treatment on insulin secretion and beta-cell mass in non-insulin dependent diabetic Goto-Kakisaki rats. Eur J Pharmacol 1998;361(2-3):243-51.

11. Zollner N, Kirsch K. Colorimetric method for determination of total lipid. Ges Exp Med 1962;135:545.

12. Fossati P, Prencipe L. Serum triglycerides determined colorimetrically with an enzyme that produces hydrogen peroxide. Clin Chem 1982;28(10):2077-80.

13. Allain CC, Poon LS, Chan CS, Richmond W, Fu PC. Enzymatic determination of total serum cholesterol. Clin Chem 1974;20(4):470-5.

14. Lopes-Virella MF, Stone P, Ellis S, Colwell JA. Cholesterol determination in high-density lipoproteins separated by three different methods. Clin Chem 1977;23(3):882-4.

15. Friedewald WT, Levy RI, Fredrickson DS. Estimation of the concentration of low-density lipoprotein cholesterol in plasma, without use of the preparative ultracentrifuge. Clin Chem 1972;18(6):499-502.

16. Trinder P. Determination of blood glucose using 4-amino phenazone as oxygen acceptor. J Clin Pathol 1969;22(2):246.

17. Reitman S, Frankel S. Glutamic-pyruvate transaminase assay by colorimetric method. Am J Clin Pathol 1957;28(1):56-63.

18. Belfield A, Goldberg DM. Hydrolysis of adenosine-monophosphate by acid phosphatase as measured by a continuous spectrophotometric assay. Enzyme 1971;12:561-6.

19. El-Baz FK, Aly HF, Abd-Alla HI, Saad S. Bioactive flavonoid glycosides and antidiabetic activity of Jatropha curcas on streptozotocin-induced diabetic rats. Int J Pharm Sci Rev Res 2014;29(2):143-56.

20. Montgomery HA, DymockJF. The determination of nitratein water. Analyst 1961;86:414-6.

21. Beutler E, Duron O, Kelly BM. Improved method for the determination of blood glutathione. J Lab Clin Med 1963;61:882-8.

22. Satoh K. Serum lipid peroxide in cerebrovascular disorders determined by a new colorimetric method. Clin Chim Acta 1978;90(1):37-43.

23. Harris RA, Padilla J, Hanlon KP, Rink LD, Wallace JP. The flow-mediated dilation response to acute exercise in overweight active and inactive men. Obesity (Silver Spring) 2008;16(3):578-84.

24. Ikebukuro K, Adachi Y, Yamada Y, Fujimoto S, Seino Y, Oyaizu H, et al. Treatment of streptozotocin-induced diabetes mellitus by transplantation of islet cells plus bone marrow cells via portal vein in rats. Transplantation 2002;73(4):512-8.

25. Matsumoto S, Koshiishi I, Inoguchi T, Nawata H, Utsumi H. Confirmation of superoxide generation via xanthine oxidase in streptozotocin-induced diabetic mice. Free Radic Res 2003;37(7):767-72.

26. Båvenholm PN, Pigon $\mathrm{J}$, Ostenson $\mathrm{CG}$, Efendic $\mathrm{S}$. Insulin sensitivity of suppression of endogenous glucose production is the single most important determinant of glucose tolerance. Diabetes 2001;50(6):1449-54.

27. Hashemnia M, Oryan A, Hamidi AR, Mohammadalipour A. Blood glucose levels and pathology of organs in alloxan-induced diabetic rats treated with hydro-ethanol extracts of Allium sativum and Capparis spinosa. Afr J Pharm Pharmacol 2012;6(21):1559-64.

28. Eddouks M, Jouad H, Maghrani M, Lemhadri A, Burcelin R. Inhibition of endogenous glucose production accounts for hypoglycemic effect of Spergularia purpurea in streptozotocin mice. Phytomedicine 2003;10(6-7):594-9

29. Ahmed HH, Aly HF, Ali SA. Potential impact of coq10 and vitamin e against (STZ) induced metabolic deterioration in the albino rats. Int J Pharm Pharm Sci 2015;7(11):176-84.

30. Ali FF, El-Baz KF, Abd El-Rahman AA, Aly HF, Mohamed AA, Saad SA. Attenuation of some metabolic deterioration induced by diabetes mellitus using different Jatropha curcas extracts. Int J Pharm Sci Rev Res 2015;30(2):164-71.

31. Noori S, Zafar H, Mahboob T. Biochemical effectiveness of cocoa powder on electrolytes homeostasis, liver and cardiac specific enzymes and renal function. Pak J Nutr 2009;8(6):882-6.

32. Rizk MZ, Aly HF, Matloub AM, Fouad GI. The antihypercholesterolemic effect of ulvan polysaccharide extracted from the green alga Ulvafasciata onaged hypercholesterolemic rats. Asian J Pharm Clin Res 2016;9(3):165-76.

33. Rizk MZ, El-Sherbiny M, Borai IH, Ezz MK, Aly HF, Matloub AA, et al. Sulphated polysaccharides (SPS) from the green alga Ulvafasciata extract modulates liver and kidney function in high fat diet-induced hypercholesterolemic rats. Int J Pharm Pharm Sci 2016;8(6):43-55.

34. Kim AR, Lee JJ, Lee YM, Jung HO, Lee MY. Cholesterol-lowering and anti-obesity effects of Polymnia sonchifolia Poepp and Endl. Powder in rats fed a high fat-high cholesterol diet. J Korean Soc Food Sci Nutr 2010;39(2):210-8.

35. Yadav YC, Srivastav DN, Seth AK, Gupta VD, Kuldeep S. Nephroprotective and curative activity of Lepidium sativum L. Seeds in albino rats using cisplatin induced nephrotoxicity. Pharmacology 2009;3:640-6.

36. Munish G, Chanchal G. Effect of Phyllanthus urinaria in biochemical profile of experimental hyperglycemic albino rats. Res J Pharm Sci 2012;1(1):2-6.

37. Zhou R, Xu Q, Zheng P, Yan L, Zheng J, Dai G. Cardioprotective effect of fluvastatin on isoproterenol-induced myocardial infarction in rat. Eur J Pharmacol 2008;586(1-3):244-50.

38. Arhoghro EM, Ekpo KE, Ibeh GO. Effect of aqueous extract of scent leaf (Ocimum gratissimum) on carbon tetrachloride (CC14) 
induced liver damage in albino wister rats. Afr J Pharm Pharmacol 2009;3(11):562-7.

39. Ogunnaike BF, Okutachi IR, Anucha ES, Gbodi OO, Shokunbi OS, Onajobi FD. Comparative anti-inflammatory activities of Jatropha curcas, Ocimum gratissimum and Solanum scabrum leaves. Nat Prod Plant Resour 2013;3(1):59-66.

40. Meira M, Da Silva EP, David J, Mand David JP. Review of the genus Ipomoea: Traditional uses, chemistry and biological activities. Rev Bras Farm 2012;22. Available from: http://www.scielo.br/scielo. php?script=sci_arttext\&pid=S0102-695X2012000300031.

41. Grace D, Mahuku G, Hoffmann V, Atherstone C, Upadhyaya HD, Bandyopadhyay R. International agricultural research to reduce food risks: Case studies on aflatoxins. Food Sec 2015;7:569-82.

42. Miyazaki K, Makino K, Iwadate E, Deguchi Y, Ishikawa F, Anthocyanins from purple sweet potato Ipomoea batatas cultivar Ayamurasaki suppress the development of atherosclerotic lesions and both enhancements of oxidative stress and soluble vascular cell adhesion molecule-1 in apolipoprotein E-deficient mice. J Agric Food Chem 2008;56(23):11485-92.

43. Yu Q, Cheng N, Ni X. Identifying 2 prenyl flavanones as potential hepatotoxic compounds in the ethanol extract of Sophora flavescens. J Food Sci 2013;78(11):1830-4.

44. Guo C, Zhang C, Li L, Wang Z, Xiao W, Yang Z. Hypoglycemic and hypolipidemic effects of oxymatrine in high-fat diet and streptozotocininduced diabetic rats. Phytomedicine 2014;21(6):807-14.

45. Prasad K, Mantha SV, KaIra J, Lee P. Hypercholesterolemia-induced oxidative stress in heart and its prevention by vitamin E. Int J Angiol 1997;6:13-7.

46. Abu-Gabal NS, Abd-Alla HI, Mohamed NZ, Aly HF, Shalaby NM. Phytophenolics composition, hypolipidemic, hypoglycemic and antioxidative effects of the leaves of Fortunella japonica (Thunb.) Swingle. Int J Pharm Pharm Sci 2015;7:55-63.

47. Dawson TM, Dawson VL. Review: Nitric oxide: Actions and pathological roles. Neuroscientist 1995;1:7-18.

48. Yücel I, Akar Y, Yücel G, Ciftçioglu MA, Keles N, Aslan M. Effect of hypercholesterolemia on inducible nitric oxide synthase expression in a rat model of elevated intraocular pressure. Vision Res 2005;45(9):1107-14.

49. Boscá L, Zeini M, Través PG, Hortelano S. Nitric oxide and cell viability in inflammatory cells: A role for $\mathrm{NO}$ in macrophage function and fate. Toxicology 2005;208(2):249-58.

50. El-Baz FK, Aly HF, Ali GI, Mahmoud R, Saad SA. Antidiabetic efficacy of Dunaliella salina extract in STZ-induced diabetic rats. Int J Pharm Bio Sci 2016;7(3):(B)465-73.

51. El-Baz FK, Aly HF, Ali GH, Abdo SM, Saad SA. Therapeutic potential of Dunaliella salina extracton lipid. Int J Pharm Bio Sci 2016;7(3):(B)414-20.

52. Pavana P, Sethupathy S, Manoharan S. Antihyperglycemic and antilipidperoxidative effects of Tephrosia purpurea seed extract in streptozotocin induced diabetic rats. Indian $\mathrm{J}$ Clin Biochem 2007;22(1):77-83.

53. Hammes HP, Bartmann A, Engel L, Wülfroth P. Antioxidant treatment of experimental diabetic retinopathy in rats with nicanartine. Diabetologia 1997;40(6):629-34

54. Townsend DM, Tew KD, Tapiero H. The importance of glutathione in human disease. Biomed Pharmacother 2003;57(3-4):145-55.

55. Meister A, Anderson ME. Glutathione Metabolism and Functions. Kroc Foundation Series 6. New York: Raven Press; 1983. p. 1-382.

56. Qi HM, Zhang Q, Zhao T, Hu R, Zhange K, Li Z. In vitro antioxidant activity of acetylated and benzoylated derivatives of polysaccharides extracted from Ulvapertusa (Cholorophyta). Bioorg Med Chem 2006;16(9):2441-5.

57. Gonzalez RC, Woods RE. Digital Image Processing. $3^{\text {rd }}$ ed. Upper Saddle River, NJ: Prentice-Hall; 2008.

58. Makni M, Fetoui H, Gargouri NK, Garoui el M, Jaber H, Makni J, et al. Hypolipidemic and hepatoprotective effects of flax and pumpkin seed mixture rich in omega-3 and omega- 6 fatty acids in hypercholesterolemic rats. Food Chem Toxicol 2008;46(12):3714-20.

59. Krentz AJ. Lipoprotein abnormalities and their consequences for patients with Type 2 diabetes. Diabetes Obes Metab 2003;5 Suppl 1:S19-27.

60. Shirwaikar A, Rajendran K, Punitha IS. Antidiabetic activity of alcoholic stem extract of Coscinium fenestratum in streptozotocin-nicotinamide induced Type 2 diabetic rats. J Ethnopharmacol 2005;97(2):369-74.

61. Hristova M, Aloe L. Metabolic syndrome - Neurotrophic hypothesis. Med Hypotheses 2006;66(3):545-9.

62. Liu X, Sun Z, Zhang M, Meng X, Xia X, Yuan W, et al. Antioxidant and anti hyperlipidemic activities of polysaccharides from sea cucumber Apostichopus japonicus. Carbohydr Polym 2012;90(4):1664-70.

63. Jang A, Srinivasan P, Lee NY, Song HP, Lee JW, Lee M, et al. Comparison of hypolipidemic activity of synthetic gallic acid-linoleic acid ester with mixture of gallic acid and linoleic acid, gallic acid, and linoleic acid on high-fat diet induced obesity in C57BL/6 Cr Slc mice. Chem Biol Interact 2008;174(2):109-17.

64. Cohen SL, Moore AM, Ward WE. Flaxseed oil and inflammationassociated bone abnormalities in interleukin-10 knockout mice. J Nutr Biochem 2005;16(6):368-74.

65. Flock MR, Green MH, Kris-Etherton PM. Effects of adiposity on plasma lipid response to reductions in dietary saturated fatty acids and cholesterol. Adv Nutr 2011;2(3):261-74.

66. Sorci-Thomas M, Prack MM, Dashti N, Johnson F, Rudel LL, Williams DL. Differential effects of dietary fat on the tissue-specific expression of the apolipoprotein A-I gene: Relationship to plasma concentration of high density lipoproteins. J Lipid Res 1989;30(9):1397-403.

67. Aly HF, Mahmoud EA, Ibrahim ME, Motawe HM, Ibrahim FM Attenuation of some metabolic deterioration induced by diabetesmellitus using Nepeta cataria extracts. J Am Sci 2010;6:436-55.

68. Bobek P, Hromadová M, Ozdín L. Oyster mushroom (Pleurotus ostreatus) reduces the activity of 3-hydroxy-3-methylglutaryl CoA reductase in rat liver microsomes. Experientia 1995;51(6):589-91.

69. Ademuyiwa O, Ugbaja RN, Idumebor F, Adebawo O. Plasma lipid profiles and risk of cardiovascular disease in occupational lead exposure in Abeokuta, Nigeria. Lipids Health Dis 2005;4:19.

70. Nofer JR, Kehrel B, Fobker M, Levkau B, Assmann G, von Eckardstein A. HDL and arteriosclerosis: Beyond reverse cholesterol transport. Atherosclerosis 2002;161(1):1-16.

71. Assmann G, Nofer JR. Atheroprotective effects of high-density lipoproteins. Annu Rev Med 2003;54:321-41.

72. Qi HM, Huang LY, Liu XL, Liu DM, Zhang QB, Liu SM Antihyperlipidemic activity of high sulfate content derivative of polysaccharide extracted from Ulvapertusa (Chlorophyta). Carbohydr Polym 2012;87(2):1637-40.

73. Sathivel A, Raghavendran HR, Srinivasan P, Devaki T. Antiperoxidative and anti-hyperlipidemic nature of Ulva lactuca crude polysaccharide on D-galactosamine induced hepatitis in rats. Food Chem Toxicol 2008;46(10):3262-7.

74. Saravanan R, Pari L. Antihyperlipidemic and antiperoxidative effect of diasulin, a polyherbal formulation in alloxan induced hyperglycemic rats. BMC Complement Altern Med 2005;5:14. 